\title{
Importation and distribution of unregistered medicines in the public sector: similarities, differences and shared challenges among Southern African Development Community (SADC) countries
}

Admire Nyika ( $\square$ adnyika@gmail.com )

University of Zimbabwe

\section{Bernard Ngara}

University of Zimbabwe

Isaac Mutingwende

University of Zimbabwe

\section{Luther Gwaza}

World Health Organization, Regulation and Prequalification Department, Access to Medicines and Health Products Division

\section{Research Article}

Keywords: Importation, Unregistered medicines, Legal provisions, Implementation, SADC

Posted Date: January 14th, 2022

DOI: https://doi.org/10.21203/rs.3.rs-1169885/v1

License: (1) This work is licensed under a Creative Commons Attribution 4.0 International License.

Read Full License 


\section{Abstract}

\section{Background}

The purpose of the study was to assess the requirements for approval of the importation of unregistered medicines for use in the public sector in the Southern African Development Community (SADC) countries.

\section{Methods}

The study reviewed the legal provisions and requirements to be fulfilled when importing unregistered medicines for the public sector in SADC countries relative to two comparators drawn from countries with stringent regulatory systems through extant document analysis. The relative implementation index score was calculated and used to measure the level of implementing legal provisions and requirements to be fulfilled. Analysis was performed using the STATA software package.

\section{Results}

Approximately 13 out of 16 SADC countries had a relative implementation index below $50 \%$. The aggregated implementation index across all SADC countries was $44 \%$, ranging from $4 \%$ to $54 \%$, while the two comparators had a relative implementation index of $81 \%$ and $85 \%$, respectively.

\section{Conclusion}

Implementing the minimum requirements for importing unregistered medicines for the public sector was deficient compared to the jurisdictions with stringent regulatory systems, and wide implementation gaps also existed within the SADC region.

\section{Background}

The use of medical products such as pharmaceuticals, biologicals including vaccines, blood products, and medical devices, including in vitro diagnostics, is essential in the healthcare system $(1,2)$. Every country should ensure an adequate supply of safe, efficacious, good quality, and affordable medical products to promote public health (3). Effective regulatory systems ensure that the medical products meet the recommended standards to protect and promote public health $(4,5)$. All countries globally are encouraged to have effective and efficient National Regulatory Authorities (NRAs)(6). However, at least $30 \%$ of the existing NRAs have constrained capacity to perform core regulatory functions $(7,8)$.

Medical products are allowed for use after the respective NRAs approve them. The requirements to obtain such approval differ among NRAs based on their regulatory capacity $(9,10)$. This regulatory review process requires a considerable amount of time and adequate skilled personnel, impacting the availability of registered medicines $(9,11)$. 
According to World Health Organization (WHO), Africa has 54 NRAs with varying capacities, but most cannot perform the critical regulatory functions. The WHO report estimates that only $30 \%$ of NRAs among its Member States can effectively and efficiently regulate medical products in their countries(12).WHO and its Member States require that medical products be registered; this involves the regulatory review of the quality, safety and efficacy data before approval for marketing $(10,11,13)$. Unregistered medicines are medical products that have not undergone evaluation and/or approval by the respective NRA in a specific jurisdiction to determine compliance with established requirements for quality, safety, and efficacy and compliance with the national or regional regulation and legislation as applicable. This medical product may or may not have obtained the relevant authorization from the NRA in the source market $(14,15)$. There is evidence to demonstrate that unregistered medicines are associated with an increased incidence of adverse drug reactions and that despite advances in medicine regulation and guidance from professional organizations, the use of unregistered medicines $(16,17)$ in at-risk populations has not reduced $(18,19)$. Moreover, the impact of unregistered medicines is greater in low and middle-income countries due to the less mature regulatory systems and financial and human capacity constraints.

Ineffective delivery of quality healthcare services has led to shortages of medicines worldwide, including the Southern African Development Community (SADC) (20-23). Medicines shortages can be worsened in the absence of functional NRAs, exposing the public to potentially unsafe medical products. Medicines shortages can also be caused by changes in pharmaceutical manufacturers' marketing strategy, supply chain challenges, unexpected surges in demand, production-related issues, global pandemics such as Ebola and Covid-19, and natural disasters such as cyclones, among others $(20,21,24)$. These factors create a vacuum for the availability of the medicines approved by the NRAs, leading to the demand and the use of medicines that have not undergone regulatory review approval. Therefore, the importation and distribution of unregistered medicines is a global phenomenon that is often necessary to bridge supply chain gaps, and this is expected to continue into the foreseeable future.

To objectively assess each NRA and create an opportunity for strengthening regulatory systems, WHO developed a Global Benchmarking Tool (GBT) (9). The GBT assesses the strengths and weaknesses in the various regulatory functions and scores the system in terms of maturity levels (ML), ranging from 1 to 4. $(2,18)$ In addition, the GBT assesses the availability of legal provisions, policies, manuals, guidelines, Standard Operating Procedures (SOPs), infrastructure, and availability of adequate and skilled personnel, which are all critical factors for effective regulation of medicines $(2,13,16)$.

The use of unregistered medicines is expected to continue for the foreseeable future, raising concern globally, as documented in previous studies(25). Of concern is that unregistered medicines' quality, efficacy, and safety remains unknown to the importing countries. Therefore, to safeguard public health, the approval processes for importing and distributing unregistered medicines should be robust to mitigate the potential risk posed by such exemptions from the normal registration processes required to protect public health. The potential increase in the risk of adverse medical events or lack of therapeutic effect is also a cause for concern with unregistered medicines $(25,26)$. 
To our knowledge, the legal provisions and requirements set by each NRAs in SADC when approving the importation and distribution of unregistered medicines, similarities, differences, robustness, and challenges remain unknown as the processes are not usually published; hence no opportunity for knowledge sharing and or transfer. The objectives of this study were to review and determine the level of implementing the legal provisions and requirements for the importation of medicines across the SADC NRAs. The study provides baseline data for creating a regional guideline for good practices when importing unregistered medicines to protect public health. The identified gaps can be included in the institutional development plans for each NRA to enhance the regulatory systems within the region.

\section{Method}

\section{Sample}

SADC has 16 Member States. The legislative instruments and guidelines from 15 SADC countries, namely Angola, Botswana, Comoros, Democratic Republic of Congo (DRC), Eswatini, Lesotho, Madagascar, Malawi, Mozambique, and Namibia, Seychelles, South Africa, Tanzania, Zambia, and Zimbabwe, were included in the analysis. No response or data was obtained from Mauritius.

\section{Source of data}

The study reviewed the legislative provisions and the requirements for the approval of importation and distribution of unregistered medicines by 15 SADC NRAs, and two comparators drawn from developed settings. Convenient selection of the two comparators was applied in this study. These two referenceNRAs are also listed as WHO-listed authorities, i.e., considered stringent regulatory authorities by WHO(27). Data on the provisions and the requirements for the approval of importation and distribution of unregistered medicines were extracted from the legislation (laws and regulations) and guidelines of the NRAs by the researchers. Additionally, 15 independent reviewers drawn from each of the NRAs were tasked to review legislative provisions and the requirements for the approval of importation and distribution of unregistered medicines from their respective NRAs. A set of 18 parameters adopted from the WHO guideline on import procedures of medical products was used in the review process (19). The themes were based on good regulatory practices for marketing authorization as detailed in WHO guidelines (28). The parameters were measured on a 4-point scale based on the GBT: no formal approach (ML 1); reactive approach ( $M L 2)$; well-functioning and integrated regulatory systems $(M L 3)$ and regulatory systems operating at an advanced level of performance and continuous improvement" (ML 4) $(2,18)$.

\section{Statistical analysis}

A Relative Implementation Index (RII) was used to assess the level of implementation of the legislative provisions and the requirements for the approval of importation and distribution of unregistered medicines, overall, for the NRAs, across each parameter, and for each of the NRAs. The RII $=\Sigma W /\left(A^{\star} N\right)$, where $W$ is the weighting given to each indicator (ranging from 1 to 4 ), $A$ is the highest weight (i.e. 4 in 
this case), and $\mathrm{N}$ is the total number of indicators assessed(29). All data analysis was carried in the STATA software package.

\section{Results}

\section{Implementation of legislative provisions and guidelines}

Most of the NRAs had legal provisions for importing unregistered medicines. The level of implementation of the recommended standards is approximately $73 \%$ for importing unregistered medicines, $58 \%$ for receiving donations, and $54 \%$ for the use of standard operating procedures and guidelines.

\section{Implementation of the requirements for assessing the quality of imported medicines}

Implementing the requirements for obtaining good manufacturing practice (GMP) approval was estimated to be $53 \%, 23 \%$ for pre-distribution analysis, $36 \%$ for batch specific data such as certificate of analysis, and $33 \%$ for pre-distribution inspection across the NRAs.

\section{Implementation of the requirements for assessing the efficacy and safety of imported medicines}

The requirement for registration in the country of origin or recognized jurisdictions was estimated to be $33 \%$ across the NRAs, $54 \%$ for implementing post-market surveillance and $14 \%$ implementation level for requirements for specific dosage forms and product-specific data. The level of implementing the requirement for product brochures containing chemical, pharmaceutical, pre-clinical pharmacological and toxicological data and, where applicable, human or animal pharmacological and clinical data with the medicine concerned was estimated to be $28 \%$ across the NRAs. Similarly, a $24 \%$ implementation level was noted across NRAs for supply history.

\section{Implementation of other additional requirements}

Assessing if a registered alternative or the registered option has not been imported in the past six months occurs in $48 \%$ of the NRAs, and $16 \%$ require a dossier to be submitted. Only $12 \%$ implementation level was observed on the requirements for inclusion in the essential medicines list (EML), and $27 \%$ implementation of requirements for a justification for an unregistered medicine. The level of implementing the requirement for restriction to emergencies, disease outbreaks, neglected disease and shortages was estimated to be $22 \%$ across the NRAs.

\section{Implementation level by country}

The overall level of implementation of the legal provisions for the importation of medicines across all the NRAs in SADC was estimated to be approximately $44 \%$, ranging from $4 \%$ to $55 \%$, while that for the comparators Canada and the United Kingdom was estimated to be approximately $81 \%$ and $85 \%$, respectively (Figure 1 ). 


\section{Discussion}

To our knowledge, this is the first study to explore the regulations and requirements for the importation of unregistered medicines and receiving donations in the SADC region. Thirteen out of the 15 SADC NRAs were estimated to be below $50 \%$ implementation level compared to above $80 \%$ for the two reference NRAs. All the SADC NRAs had a score of less than $60 \%$. The wide-ranging implementation index scores also confirm the varying regulatory capacities within the region. Our results show that the SADC countries have not fully implemented most of the expected risk-based requirements for approving requests for importing unregistered medicines. The legislation and guidelines in these countries were not meeting minimum requirements set out in the WHO guideline on import procedures for medical products. Such procedures included risk-based testing, an inspection of consignments, among others (19).

Our study focused on the regulation of unregistered medicines, an area often neglected and not fully addressed in ongoing efforts to strengthen regulatory systems. Nonetheless, the results are consistent with previous reports; for example, the estimates that only $30 \%$ of NRAs among its Member States can effectively and efficiently regulate medical products in their countries(30). The results are also consistent with other studies that observed that legal frameworks lacked or were fragmented in most African countries $(2)(2,6)$. Additionally, some studies have shown that implementing medicines control regulation on the importation, use, and reporting of adverse drug reactions in developing countries is by far still too low compared to the levels in high-income countries $(31,32)$. As a result, inadvertently, NRAs in SADC, or similar settings, allow the importation of medicines whose quality is unknown and not being assessed.

SADC is a region with diverse countries across several dimensions, for example, population sizes, geographical sizes, the size of the pharmaceutical market, economic levels, and regulatory capacities. The study, therefore, encompassed many different factors, and results can be generalized to countries in Africa or similar settings. The GBT is considered a well-established tool through a robust process and applied globally. Therefore, the indicators used in the study are considered fairly validated. The basis for requirements used in the study was the requirements in WHO guidelines on import procedures of medical products, requirements for obtaining marketing authorization, and those set out by ML4 NRAs.

Given that unregistered medicines should be imported under exceptional circumstances and in some cases during emergencies, it may not always be feasible to implement all the requirements for granting marketing authorizations. Nonetheless, even in those circumstances, there remains a need to assess the medicines' quality, efficacy, and safety to protect public health based on a risk-based approach. Therefore, the results are based on comprehensive parameters that were considered sufficient to reflect the implementation of the regulatory function for exemptions.

Analysis of legislation and guidelines is fairly robust and objective; however, interpretation of the results should contextualize the different legislative systems across the countries and implications at the operational level when implementing the legislation provision in practice. Therefore, further studies analysing data on the importation of unregistered medicines and practices among the regulators are 
required. In other words, the implementation index values alone may not directly indicate public health risk for individual countries. Other factors should be considered, for example, the extent to which unregistered medicines are supplied in the public sector, the supply chain of such unregistered products, and the quality assurance mechanisms implemented by the procurement agencies. For instance, United Nations Agencies and other international organizations largely procure WHO-prequalified products or products approved by WLAs. Therefore, while these products may be unregistered in the SADC NRAs, their quality, safety and efficacy are known and established $(29,30)$

\section{Conclusion}

Implementing the standard guidelines for importing unregistered medicines in SADC is still very low, with an overall implementing index of $44 \%$ compared to the reference NRAs with index values above $80 \%$. The region is heterogeneous, with a wide range among the NRAs. The low implementation levels of recommended standards for unregistered medicines increase the risk of potentially exposing the population in the region to unsafe medical products of variable quality and effectiveness. The SADC countries should learn from other NRAs and implement a risk-based and more robust process for regulating unregistered medicines.

\section{Declarations}

\section{Ethics approval and consent to participate}

The study obtained approval to carry the study from the Joint Research Ethics Committee (JREC) For the University of Zimbabwe, Faculty of Medicine and Health Sciences (FMHS) and Parirenyatwa Group of Hospitals (PGH), (JREC - JREC/148/2021). Each participant provided informed consent to participate in the study. The study was performed while observing good clinical practices and in accordance with the Helsinki declaration.

\section{Consent for publication}

Not Applicable.

\section{Availability of data and material}

The study is yet to publish the data to the public. However, the data can be available upon request and approval from the corresponding author.

\section{Competing interests}

The authors declare that there is no conflict of interest.

\section{Funding}


No funding was used for this study.

\section{Authors' Contributions}

A.N and L.G. were involved in conceptual development. A.N, B.N., I.M. and L.G. were involved in full proposal development. A.N and B.N were involved in data collection, management and analysis. A.N, B.N and L.G were involved in the interpretation and discussion of results. A.N and B.N were involved in coming up with the draft manuscript. All the authors have read and approved the manuscript.

\section{Acknowledgements}

The authors would like to acknowledge the study participants for affording their time in participating in the survey.

\section{References}

1. Kaakeh R, Sweet B v., Reilly C, Bush C, DeLoach S, Higgins B, et al. Impact of drug shortages on U.S. health systems. American Journal of Health-System Pharmacy. 2011 Oct 1;68(19):1811-9.

2. Khadem Broojerdi A, Baran Sillo H, Ostad Ali Dehaghi R, Ward M, Refaat M, Parry J. The World Health Organization Global Benchmarking Tool an Instrument to Strengthen Medical Products Regulation and Promote Universal Health Coverage. Frontiers in Medicine. 2020 Aug 19;7.

3. SEVENTY-FIRST WORLD HEALTH ASSEMBLY Addressing the global shortage of, and access to, medicines and vaccines. [cited $2021 \mathrm{Jul}$ 21]; Available from: http://www.unsgaccessmeds.org/finalreport,

4. Reggi DrV. Medicines Regulatory Harmonization: International Collaboration as a Key to Improve Public Health: https://doi.org/105301/maapoc0000001 [Internet]. 2016 Dec 7 [cited $2021 \mathrm{Jul}$ 21];1:maapoc.0000001. Available from: https://journals.sagepub.com/doi/full/10.5301/maapoc.0000001

5. M N-S, A A. The African medicines regulatory harmonization initiative: rationale and benefits. Clinical Pharmacology and Therapeutics [Internet]. 2011 Feb 1 [cited 2021 Jul 21];89(2):176-8. Available from: https://europepmc.org/article/med/21252936

6. Sillo H, Ambali A, Azatyan S, Chamdimba C, Kaale E, Kabatende J, et al. Coming together to improve access to medicines: The genesis of the East African Community's Medicines Regulatory Harmonization initiative. PLOS Medicine [Internet]. 2020 Aug 1 [cited 2021 Jul 22];17(8):e1003133. Available from: https://journals.plos.org/plosmedicine/article?id=10.1371/journal.pmed.1003133

7. Mcauslane N, Cone M, Collins J, Walker S. Emerging Markets and Emerging Agencies: A Comparative Study of How Key Regulatory Agencies in Asia, Latin America, the Middle East, and Africa are Developing Regulatory Processes and Review Models for New Medicinal Products. Therapeutic Innovation \& Regulatory Science. 2009;43(3):349-59. 
8. Keyter A, Banoo S, Salek S, Walker S. The South African Regulatory System: Past, Present, and Future. Frontiers in Pharmacology. 2018 Dec 4;0:1407.

9. Guzman J, O'Connell E, Kikule K, Hafner T. The WHO Global Benchmarking Tool: a game changer for strengthening national regulatory capacity. BMJ Global Health [Internet]. 2020 Aug 1 [cited 2021 Jul 21];5(8):e003181. Available from: https://gh.bmj.com/content/5/8/e003181

10. Ndomondo-Sigonda M, Miot J, Naidoo S, Masota NE, Ng'andu B, Ngum N, et al. Harmonization of medical products regulation: a key factor for improving regulatory capacity in the East African Community. BMC Public Health. 2021 Dec 1;21(1).

11. Ndomondo-Sigonda M, Miot J, Naidoo S, Dodoo A, Kaale E. Medicines Regulation in Africa: Current State and Opportunities. Pharmaceutical Medicine. 2017 Dec 1;31(6):383-97.

12. Emp Annual Report W, Access T. WHO EMP ANNUAL REPORT 2017: TOWARDS ACCESS 2030.

13. Manghani K. Quality assurance: Importance of systems and standard operating procedures. Perspectives in Clinical Research [Internet]. 2011 [cited 2021 Jul 21];2(1):34. Available from: /pmc/articles/PMC3088954/

14. Junod SW, Beaver WT. FDA and Clinical Drug Trials: A Short History. [cited 2021 Jul 21]; Available from: www.fda.gov

15. lyengar S, Hedman L, Forte G, Hill S. Medicine shortages: A commentary on causes and mitigation strategies. BMC Medicine. 2016 Sep 29;14(1).

16. Vi R. WHO Global Benchmarking Tool (GBT) for Evaluation of National Regulatory System of Medical Products.

17. Sutherland $A$, Waldek $S$. It is time to review how unlicensed medicines are used. European Journal of Clinical Pharmacology [Internet]. 2015 Sep 13 [cited 2021 Jul 21];71(9):1029. Available from: /pmc/articles/PMC4532700/

18. Evaluating and publicly designating regulatory authorities as WHO listed authorities [Internet]. [cited $2021 \mathrm{Jul}$ 21]. Available from: https://www.who.int/publications/i/item/9789240023444

19. Annex 5 Guidelines on import procedures for medical products Background. [cited 2021 Jul 21]; Available from: http://apps.who.int/medicinedocs/documents/s21962en/s21962en.pdf

20. C Yang LWWCWZQSZL. Current Situation, Determinants, and Solutions to Drug Shortages in Shaanxi Province, China: A Qualitative Study. PloS One. 2016 Oct 1;11(10):e0165183-e016518e.

21. Acosta A, Vanegas EP, Rovira J, Godman B, Bochenek T. Medicine Shortages: Gaps Between Countries and Global Perspectives. Frontiers in Pharmacology. 2019 Jul 19;10.

22. $\mathrm{K}$ Heiskanen RARKPKJT. The reasons behind medicine shortages from the perspective of pharmaceutical companies and pharmaceutical wholesalers in Finland. PloS One. 2017 Jun 1;12(6):e0179479-e.

23. Modisakeng C, Matlala M, Godman B, Meyer JC. Medicine shortages and challenges with the procurement process among public sector hospitals in South Africa; findings and implications. BMC 
Health Services Research 2020 20:1 [Internet]. 2020 Mar 19 [cited 2021 Jul 21];20(1):1-10. Available from: https://bmchealthservres.biomedcentral.com/articles/10.1186/s12913-020-05080-1

24. lyengar S, Hedman L, Forte G, Hill S. Medicine shortages: a commentary on causes and mitigation strategies. BMC Medicine 2016 14:1 [Internet]. 2016 Sep 29 [cited 2021 Jul 21];14(1):1-3. Available from: https://bmcmedicine.biomedcentral.com/articles/10.1186/s12916-016-0674-7

25. Kelesidis T, Kelesidis I, Rafailidis PI, Falagas ME. Counterfeit or substandard antimicrobial drugs: A review of the scientific evidence. Journal of Antimicrobial Chemotherapy. 2007 Aug;60(2):214-36.

26. Substandard and falsified medical products [Internet]. [cited $2021 \mathrm{Jul} 21]$. Available from: https://www.who.int/news-room/fact-sheets/detail/substandard-and-falsified-medical-products

27. WHO-Listed Authority (WLA) [Internet]. [cited 2021 Dec 6]. Available from: https://www.who.int/initiatives/who-listed-authority-reg-authorities

28. TRS 1033 - 55th report of the WHO Expert Committee on Specifications for Pharmaceutical Preparations [Internet]. [cited 2021 Jul 21]. Available from: https://www.who.int/publications/i/item/55th-report-of-the-who-expert-committee-on-specificationsfor-pharmaceutical-preparations

29. Rajgor M, Paresh C, Dhruv P, Chirag P, Dhrmesh B. RII \& IMPI: EFFECTIVE TECHNIQUES FOR FINDING DELAY IN CONSTRUCTION PROJECT [Internet]. International Research Journal of Engineering and Technology. 2016. Available from: www.irjet.net

30. Roth L, Bempong D, Babigumira JB, Banoo S, Cooke E, Jeffreys D, et al. Expanding global access to essential medicines: investment priorities for sustainably strengthening medical product regulatory systems. Globalization and Health 2019 14:1 [Internet]. 2018 Nov 1 [cited 2021 Jul 21];14(1):1-12. Available from: https://globalizationandhealth.biomedcentral.com/articles/10.1186/s12992-0180421-2

31. Gagnon M-A. Drug Shortages: Searching for a Cure. Healthcare Policy [Internet]. 2012 [cited 2021 Jul 21];7(4):10. Available from: / pmc/articles/PMC3359080/

32. T B, V A, A A, B A, I de MB, Z B, et al. Systemic Measures and Legislative and Organizational Frameworks Aimed at Preventing or Mitigating Drug Shortages in 28 European and Western Asian Countries. Frontiers in pharmacology [Internet]. 2018 Jan 18 [cited 2021 Jul 21];8(JAN). Available from: https://pubmed.ncbi.nlm.nih.gov/29403372/

\section{Figures}




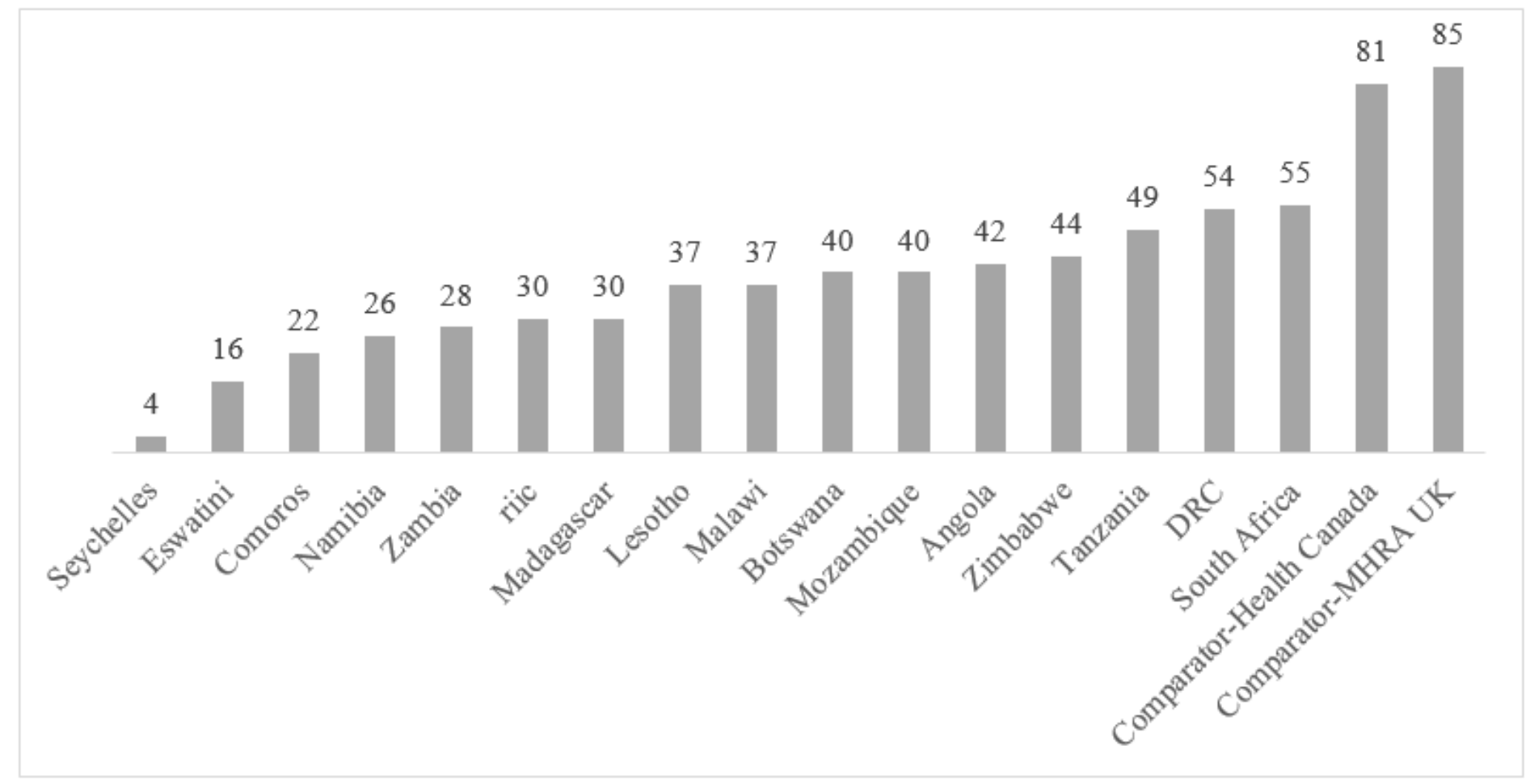

Figure 1

Relative Implementation Index (\%) by country including examples of comparators from developed settings 